\title{
Power in The People: Strengths and Hope
}

\author{
Dennis Saleebey
}

\begin{abstract}
The strengths perspective and resilience literature suggest that social workers may learn from those people who survive and in some cases flourish in the face of oppression, illness, demoralization, and abuse. Social workers need to know what steps these natural survivors have taken, what processes they have adopted, and what resources they have used. In this article, written specifically for Advances in Social Work, Dennis Saleebey discusses the central tenets of strengths-based practice.
\end{abstract}

Keywords: Strengths, resilience, strengths-based, social work, hope, diagnostic strengths manual

$\mathrm{T}$

he wildly expanding resilience literature compels us to regard and respect the qualities, traits, virtues, and resources that people develop, acquire, and accumulate as they confront and struggle with the challenges in their lives. The strengths perspective acknowledges that reality, too. In addition, the strengths approach obligates us to understand-to believe-that everybody (no exceptions here) has external and internal assets, competencies, and resources. These may be a realized part of a person's life or they may be inchoate-unrealized and unused. But the understanding and work of people who employ a strengths perspective is driven by the search for, the definition, and employment of peoples' resources in helping them walk, however hesitatingly, in the direction of their hopes and dreams. We are called to venerate the remarkable abundance of human experience, to acknowledge that every individual, family, and community has an array of capacities and skills, talents and gifts, wiles and wisdom that, in the end are the bricks and mortar of change. We must assume the humble stance that we cannot know, except in the most obvious of cases, the upper limits of a person's capacity to grow and change. The strengths perspective holds firm the idea that everyone who struggles learns something from their struggle and develops capacities and traits that may ultimately turn out to be bountiful resources in moving towards a better life. It is to assert that everyone has dreams, visions, and hopes even though they may currently be dashed on the shoals of disease, oppression, poverty, or muted by a run of rotten luck.

The work of the strengths approach is the work of empowerment-helping individuals, families, and communities see and utilize their capacities; recognize the options open to them; understand the barriers and scarcities they may face; surface

Dennis Saleebey, Ph.D. is Professor, University of Kansas School of Social Welfare, Lawrence, Kansas 66045 USA. 
their hopes and aspirations; and align them with their inner and outer resources to improve the quality of their lives (Cowger, 1994; Rapp, 1998; Saleebey, 1997). Empowerment is both a process and a goal. As a goal, those who are empowered seek a firmer sense of purpose, a place to be and belong, an operating fund of esteem, the possibility of choice, connections to resources and ties to others, and a palpable awareness of their achievements-both in the short run and in the distant future. Empowerment as a process is the collaboration between, say a social worker and a family or individual, working together on a mutually-crafted project that in some sense will move people closer to their visions and aspirations (Rapp, 1998). The strengths perspective, then, is about "uncovering, naming, embellishing, and celebrating abilities, talents, and aspirations in the service of desired change"(Weick \& Saleebey, 1995).

The strengths perspective is a way of thinking about and looking at the people social workers help and the work they do with clients. In a sense it is a paradigm shift, although social workers have insisted for years that they build on the strengths of clients. But it is only recently that there has been any significant work - whether inquiry and research or clinical practice or community workfocused on developing a strengths perspective. In addition, there are concurrent developments in other areas that provide conceptual and ideological support for this framework for professional thinking and doing. These include, among others: empowerment and liberatory approaches (many of which have been built on liberation theology and the social activism of the '60s and '70s); the resilience literature; healing and wellness practice and inquiry; solution-focused orientations, as well as narrative approaches to practice (see Saleebey, 1996). While these are all different in many ways, they include some common understandings:

- People who confront stress almost always develop some ideas, capacities, traits, or defenses that may subsequently stand them in good stead. Heretofore, social workers have been much too avid in looking at the impediments and injuries, the deficits, and desolation rather than people's compensating and transformative responses to the challenges they confront.

- Even in the most demanding, tough, lean, and mean environments, there are natural resources-individuals and families, churches, associations, groupsavailable to individuals, groups, and families. While some are clearly more bountiful than others, all environments have assets (Kretzmann \& McKnight, 1993).

- Even though people may have labored under years of the blame and disapproving opinions of others or self-criticism, habitual pessimism, or unfortunate life decisions, at some level they almost always know what is right for them.

- As a species, humanity surely has-or we would not have survived thus far-an innate capacity for health and self-righting.

- Healing, transformation, regeneration, and resilience almost always occur within the confines of a personal, friendly, supportive, and dialogical relationship. Whether a physician, social worker, psychologist, friend, or relative, the more the power of a caring relationship is actualized with those served, the better for the individual's future and for social work's equipoise. 
- Everyone has knowledge, talents, capacities, skills, and resources that can be used to help move them towards their aspirations, solve problems, meet their needs, and bolster the quality of their lives.

- A positive orientation to the future is far more important in the long run for healing and helping than an obsession with a dark and disappointing past.

- Every maladaptive response or pattern of behavior may also contain the seeds of a struggle for health and self-righting.

To sum up: Imagine an equilateral triangle. The left angle is fronted by the letter $\mathrm{C}$; the angle to the right by the letter $\mathrm{R}$. The apex of the triangle is topped with the letter $\mathrm{P}-\mathrm{CPR}$, as it were. $\mathrm{C}$ represents capacities, competencies, and character. $\mathrm{P}$ stands for promise and possibility. R symbolizes resources, resilience, and reserves. ${ }^{1}$ These make up the dynamic core of a strengths-based approach to practice. All three must be a part of any kind of healing or helping.

Much of the impetus for developing and emerging a strengths/resilience-based practice comes from American society's preoccupation and fascination with pathology, problems, moral and interpersonal aberrations, violence, and victimization. Add to that the continuing penchant towards "medicalizing" and "pathologizing" almost every pattern, habit, trait, and inclination of human behavior and one has an intoxicating mix of diagnoses, labels, and identities at the ready-all broadcasting one's abnormalities, disorders, weaknesses, fallibilities, and deficits (Kaminer, 1993; Peele, 1989; Peele \& Brodsky, 1991; Rieff, 1991). But important, too, has been the developing realization that the social worker's focus on aberrations and problems has not yielded much in the way of social betterment or the lessening of the incidence and prevalence of various disorders (Hillman \& Ventura, 1992). Likewise, there is a growing body of evidence that the linchpin of many theories of disorder and mental illness - that childhood troubles of various kinds are fateful for the development of pathology in adulthood-is not very powerful or convincing (Lewis, 1997).

It needs to be understood that a strengths perspective does not require one to blithely ignore or mute the real pains and troubles that afflict children, groups, families, and classes of people. Poverty is real. ${ }^{2}$ Child sexual abuse is real. Violence is real. Cancer is real. Schizophrenia is real. Racism is real! The strengths perspective does not require one to discount the grip and thrall of addictions or the humiliating, frightening anguish of child abuse, or the unbidden disorganization and confusion of psychosis. But from the vantage point of a strengths perspective, it is as wrong to deny the possible just as it is to deny the problem. And the strengths perspective does decry the intemperate reign of psychopathology and illness as the central civic, moral, and medical categorical imperative. Adherents of the strengths perspective do not believe, with good reason, that most people who are the victims of abuse or their own rampant appetites, or that all people who have been traumatized inevitably become damaged goods. Followers of the strengths approach do believe that the recovery movement, now so removed from its original boundaries and intent, has:

...pumped out a host of illnesses and addictions that were by earlier standards, mere habits, some good, some bad. Everywhere publicly, social work- 
ers find people talking freely, if not excitedly, even proudly about their compulsions-whether it be gambling, sex, exercise, or the horrible desire to please other people. We are awash in a sea of codependency, wounded inner children, and intimacy crises. (Wolin \&Wolin, 1993, p. 7)

Old paradigms die hard. Theories about patients, clients, victims, and the disadvantaged have been around for a while. ${ }^{3}$ On the one hand, it is good that the attic door has been opened so that women and children who have been or who are abused can tell their story. On the other hand when that door has been opened, social workers have failed to see all that was in there-including a variety of resources and possibilities. Defining these heretofore silent ones as victims seemed initially to be a service to them. But unfortunately, victim has become for far too many a master status (Becker, 1972), a controlling set of expectations, norms, images, and behaviors that have become hardened over time, difficult to penetrate, and supercede every other element of identity (one becomes, for example, a schizophrenic violinist or a gay plumber). Worse yet, many people are invited or persuaded to think of themselves as victims when they have experienced only the bumps and bruises that many can expect at some point in our lives. The same might be said of the recovery movement. In spite of the widespread good it has done, it has now spread so widely and captivated so many people that its good is obscured by its overweening dictates (Kaminer, 1993; Peele \& Brodsky, 1991).

\section{THE CORE CONDITIONS OF CHANGE}

One way to understand the orientation of those who adhere to a strengths-based approach to practice is to ask, What are the factors in life and in helping that make things go well? It is odd, when you think of it, that even though we know that most people in the midst of significant challenges and stresses do better than we might expect and do not eventually succumb to the pressures of their lives, that social workers know so little about them. On the other hand, they have a prodigious lore about those who, at least initially, fall or fail under these stresses and ordeals. Social workers' knowledge about those who change naturally and spontaneously everyday is trifling by comparison. So what does one know about discovering and building upon strengths? There are ideas, hints, and data everywhere but let us look at one perspective that this author finds rich in implication. In his review of the efficacy of psychotherapy studies conducted over many years, Michael Lambert (1992) says there are four factors that account for most of the positive change in individuals and families. These are plump with inferences for strengths-based approaches.

The largest share of the benefit experienced by individuals can be attributed to their personal and social resources, as well as contingent factors (luck) that intercede in their lives. (Lambert calls them extra-therapeutic change factors that aid in positive change, whether or not an individual ever experiences psychotherapy.) The matrix of clients' lives goes a long way toward explaining how they might react: their strengths and assets, how they see their misery (their theory) and motivation, their social supports, and the contingent factors that move inexplicably in and out of their lives. This means being mindful of things in a person's world-relationships, culture, opportunities- those conditions and people that might be positive, supportive, helpful, or even therapeutic. It also means listening and looking for 
evidence of the resources and aptitudes of clients as they tell their stories. These speak to the power of context as well-those micro-environments, the intimate spaces and places where people live and work, that have a powerful impact on how one acts, thinks, and feels. We are exquisitely sensitive to changes in context, says Malcolm Gladwell (2000). He claims that the power of context is revealed in the "broken windows" theory of Harvard criminologists James Q. Wilson and George Kelling. Basically, the idea is that if windows are broken in a neighborhood, the walls are covered with graffiti, lots are filled with trash and refuse, etc., people conclude that no one is taking care of this place, no one cares, and no one is in charge. It is because of those very assumptions that these small environments then become targets for criminals - no one is concerned or has ownership and no one will notice. Many cities, notably New York, have begun to look at this and by simply repairing windows, erasing graffiti, cleaning up lots, keeping at it, and involving neighbors in the project, they find things begin to change. A still more positive note: in many neighborhoods across the country, especially economically-distressed ones, people, without knowing its name, are beginning to put the brokenwindows theory into operation and taking it a step further: painting murals, growing community gardens, building sculptures, and refurbishing playgrounds and parks. The context becomes more livable, more humane, more interesting, and very importantly, more hopeful (Delgado, 2000; Gladwell, 2000).

The second most powerful force for change is the character and tenor of the helping relationship (common factors, according to Lambert). The quality of the relationship between helper, physician, and client and patient has always been understood (and in some cases undervalued) as a powerful tool for healing. Hans Strupp (1995), who has studied the effectiveness of psychotherapy for decades, said that the relationship is the sine qua non of all forms of therapy. It is the medium of change, a dynamic that is not to be underestimated. The important elements of that kind of relationship are well-known, thanks in large part to the pioneering work of Carl Rogers (1951): respect, genuineness, concern, collaboration, and empathy. In addition, release of tension, reassurance, the alliance forged with the client, and direct activity play a role here. If healers are seen as nonjudgmental, trustworthy, caring, and expert, they have some influential tools at hand, whether they are addressing the depths of a serious depression or the disappointments and pains of unemployment. A relationship of this sort provides a milieu and context for confronting the difficult and considering the imaginable.

The third and fourth factors, roughly equal in their impact, are the placebo effect and the technical operations and methods of the theory employed by the helper (for example, family systems, cognitive, or behavior therapy). We will more closely examine the power of expectancy and the placebo below. The methods of theory carry with them assumptions about cause, the nature of the problem, as well as directives about what to do. But, to a significant extent, they succeed or fail because of the presence (or lack of it) of these other, apparently more salient, factors (for an excellent discussion of these factors, see Miller, Duncan, \& Hubble, 1997).

Of great interest to those who subscribe to a strengths-based orientation is the influence of expectancy, hope, and the placebo effect. Consider the following. 
Michael Fisher (2000) reports that in the 1950s at the University of Kansas Medical Center in order to test a new medical procedure for the treatment of angina, surgeons performed real operations on one group of male patients with angina and a "placebo operation" on the other group. The placebo group was told they were going to have heart surgery; they were given a local anesthetic and incisions were made in their chests. But no operation was done. The surgeons merely worked somewhat, and the patients had the scars and pain to indicate that they actually had surgery (the ethics of this are distressing, and this author assumes that such an experiment would not happen today, but he really does not know for sure). Seventy percent of those who had the real surgery reported long-term improvement in their angina; but all of the placebo group did, as well. It is not at all uncommon in tests of psychoactive drugs for the placebo groups to show improvements ranging anywhere from 25 to $60 \%$. The extent that the real drug is better than the placebo is thought to be the extent that the drug is effective. But one cannot say, for instance, just how much of the effect of the real drug is also a placebo phenomenon. In more recent years, people have been getting an "active placebo" from which they experience side effects. People are more likely to get better on active placebos because they experience side effects, which convince them that they are getting a real and powerful drug. Joseph Arpala reports that a study by Fisher and Greenberg revealed that in 30 to $40 \%$ of all the studies of antidepressant drugs and placebos they reviewed, the placebo was as powerful or therapeutic as the drug (Arpala, 2000).

So what is happening here? Many things, no doubt. One possibility that many have proposed is that when people are sick and have an expectation, thanks to a procedure or pill, they get better. There is an "unconscious" mobilization of the healing systems within, whether it is the psychoneuroimmune system, endorphins (endogenous morphine produced by the body), or a parasympathetic nervous system relaxation response that lowers, among other things, cortisol, the production of which is related to stress, or some unknown process. Perhaps even more important here is the expectation of the healer that the patient will get well, the gathering of hope and possibility that things will be different in the future. Social workers spend much of their possible good will hinting or directly saying that things will not be better; that once stuck, hurt, disappointed, abused, or ill that clients will always suffer scars, or the effects of these will continue to reverberate in one way or another throughout our lives. It is not just the individual's expectation that he or she will recover, rebound, or do better; it is the unmistakable expectation of the social worker, physician, healer, minister, teacher, coach, relative, friend, or parent that they will. This is the attitude and belief that "we" can make it, "we" can leap the hurdle, climb the wall, escape the burden. "We" may need help. It may take time, but this author's belief in the individual is constant and unwavering. As a child, heretofore defined as "at-risk," this author sees the patient, as Beth Blue Swadener says, as a child "at promise" (Swadener, 1995).

This author thinks the two key ideas here are hope and possibility. Oddly enough, there has been much conceptual work and actual application of ideas related to hope, anyway-more than one might think. C. R. Snyder, the University of Kansas, has done considerable work in this area. Hope is also very much a part 
of the strengths perspective and the recovery and resilience movements. This author cannot "hope" to reflect the depth of work he and others have done but can begin with a quote from the late Paulo Freire, one of the most eloquent spokespersons for the oppressed worldwide. His book, Pedagogy of the Oppressed (2000), should be required reading for all social workers. In Pedagogy of Hope, Freire wrote before his death:

There is no change without the dream, as there is no dream without hope.

(1996, p. 91)

Hope is about imagining the possible, the "untested feasible," as Freire would have it. But more specifically, it is about thinking of one's self as an agent, able to effect some change in one's life, having goals that not only have promise but also pathways to their accomplishment-pathways that may be short or long, full of ruts or smooth, well-lit or darkened. As social workers, we consort with the subjunctive, the possible, and help to assure the agency of others, working on fashioning their hopes into goals and finding, as partners with them, those pathways to promise. In one sense, it matters little whether one reaches the end of the journey but merely that one begins the journey and reaches some of the stops along the way (Snyder, 2000).

So, the expectation that one will get better; that there is a chance that the odds can be beat; that one has within the power to transform or at least fight the disease process; this author's expectation as a friend, intimate partner, or social worker that the client will do as well as possible when confronted with whatever difficulties they have, are all extremely important elements in recovery or at least the progress of the illness.

\section{ELEMENTS OF STRENGTHS-BASED PRACTICE}

There are some root principles of strengths-based practice that should not be ignored. They are disarmingly simple but difficult to put into practice because they run counter to some of the thinking that characterizes some practices today.

1. Believe the client and believe in the client. Social workers are sometimes encouraged by our own experience or by the expectations of others to disbelieve clients. We are leery of being trumped or duped by the artful manipulator or the deft sociopath. But, until proven otherwise, believing the client and believing in the client are two of the most powerful tools for engaging clients in what is a most difficult and arduous task — making life better (De Jong \& Miller, 1995).

2. Affirm and show interest in the client's view of things. It is the narratives and stories that clients bring to us and share with us that allow us to discover who they are, what they know, what virtues they possess, what troubles they have faced, and what dreams they have (Hoyt, 1996).

3. A focus on the dreams, hopes, and visions of people encourages them to begin thinking subjunctively about what might be and how it might come about. Troubles may trump their ability to do this, but at some point, it is the possible, the promise that drives the engine of change (Snyder, 2000).

4. Central, of course, to the strengths approach to practice is to begin making an accounting of the assets, resources, reserves, and capacities within the client and 
in the environment—family, extended family, neighborhood, and institutions (like churches, schools, and informal associations). This inventory of strengths should be every bit as detailed, descriptive, and refined as the diagnostic categories of the DSM-IV-TR (American Psychiatric Association, 2000). In that spirit this author offers an example of an imagined doppleganger of the DSM IV-the Diagnostic Strengths Manual. Under the section 300.00 Estimable Personal Qualities, we find:

\subsection{Trustworthiness}

Criterion A. For at least six months, nearly every day, the individual has exhibited at least three of the following:

1. Has done what he or she promised.

2. Kept at a task that needed to be done despite problems and obstacles.

3. Did not reveal a confidence.

4. Stuck by a colleague, friend, or relative during a difficult time.

5. Did more than expected.

Criterion B. This is not better explained by co-dependency or the pathological desire to please.

Criterion C. Such behavior must have improved the lives of other people at some cost to the person's own comfort.

Criterion D. Rule out the possibility of a self-seeking desire to cash in on these loyalties later. (Saleebey, in press)

Social workers need to develop fully as lexicon, an encyclopedia of strengths so that they have a language and imagery as compelling and captivating as that found in the DSM-IV-TR.

5. Believe that there are forces for healing, self-righting, and wisdom within or around the person or family and begin to search for and employ them in the service of achieving goals on the path to the dream. Many observers, some clinicians, and researchers have begun to realize just how potent natural forces for recovery and transformation can really be (Deegan, 1996; Mills, 1995).

In summary, to enlist participation, involvement, and to engage individuals, families, and/or communities: a) assume a positive, collaborative demeanor; b) radiate the resilience attitude (see above); c) rely on indigenous wisdom, resources, and natural assets, capitalizing on what people know, what they can do, and where they want to go; d) convey positive expectancies, affirmations of the possible; e) be engaging, likable, credible, responsive, working eyeball-to-eyeball, shoulder-to-shoulder with individuals, families, and community members and; f) be flexible and willing to assume many perspectives and take on many roles.

To discover the strengths and health within: a) develop an enriched roster, an exceptional accounting of exceptions, resources, assets, and possible solutions or pathways to goals; b) find and celebrate, draw lessons from the times where the individual, family, or community has surmounted adverse conditions and bad luck, as well as their own harmful decisions; c) seek out "survivors pride" (Wolin \& 
Wolin, 1993) - that spark of recognition and esteem that comes from having met challenges and survived them; d) always seek to discuss and imagine how things could be otherwise, what a dream fulfilled would feel, taste, smell, and look like; e) seek out, elaborate, and employ the client's theory of change about how to make it to a better life; f) celebrate success; g) think small but think success when developing goals and; g) look around, look ahead, but try not to look back.

\section{CONCLUSIONS}

At the very least, the strengths perspective and the resilience literature obligate us to understand that however downtrodden, beaten up, sick, or disheartened and demoralized, individuals have survived, and in some cases even flourished. They have taken steps, summoned up resources, coped, or maybe just raged at the darkness. Social workers need to know what they have done, how they did it, and what resources provided ballast in their struggles. People are always engaged in their situations, working on them even if they just decide to resign themselves to their fate. Circumstances can overwhelm and debilitate. We do know a lot about that. But dire circumstances can also bring a surge in resolve and resilience. We must know more about that and how to make an alliance with those forces.

\section{Endnotes \\ ${ }^{1}$ Thanks to my daughter, Meghan, a social worker, for this scheme. \\ 2The designations "schizophrenia," "poverty," etc. are linguistic and social constructions that carry freight on their own, but the human anguish of the experience is unmistakable. \\ ${ }^{3}$ We have a variety of designations for those whom we think of as "other" or "different" from the rest of us-either by their own doing or by the malfeasance of others.}

\section{References}

American Psychiatric Association. (2000). Diagnostic and Statistical Manual IV-Text Revision. Washington, DC: The American Psychiatric Association Press.

Arpala, J. (August, 2000). Sweet sabotage: How sugar pills compromise drug trials. Psychology Today, 32, 66. Becker, H. S. (1972). Outsiders: Studies in the sociology of deviance. Glencoe, IL: The Free Press.

Cowger, C. D. (1994). Assessing client strengths: Clinical assessment for client empowerment. Social Work, 39, 262-268.

Deegan, P. E. (1996). Recovery as a journey of the heart. Psychiatric Rehabilitation Journal, 19, 91-97.

De Jong, P., \& Miller, S. D. (1995). Interviewing for client strengths. Social Work, 40, 729-735.

Delgado, M. (2000). Community social work practice in an urban setting: The potential of a capacityenhancement perspective. New York: Oxford University Press.

Fisher, M. J. (October, 2000). Better living through the placebo effect: It pays to believe. The Atlantic Monthly, 286, 16-18.

Freire, P. (1996). The pedagogy of hope: Reliving pedagogy of the oppressed. New York: Continuum.

Freire, P. (2000). The pedagogy of the oppressed (3rd ed.). New York: Continuum.

Gladwell, M. (2000). The tipping point: How little things can make a big difference. Boston: Little, Brown and Company. 
Hillman, J., \& Ventura, M. (1992). We've had one hundred years of psychotherapy and the world is getting worse. San Francisco: Harper San Francisco.

Hoyt, M. F. (1996). Introduction: Some stories are better than others. In M. F. Hoyt (Ed.), Constructive therapies 2 (pp. 1-32). New York: The Guilford Press.

Kaminer, W. (1993). I'm dysfunctional, you're dysfunctional. New York: Vintage Books.

Kretzmann, J. P., \& McKnight, J. L. (1993). Building communities from the inside out. Evanston, IL: Center for Urban Affairs and Policy Research, Northwestern University.

Lambert, M. J. (1992). Implications of outcome research for psychotherapy integration. In J. C. Norcross \& M. R. Goldfried (Eds.), Handbook of psychotherapy and behavior change (pp. 94-129). New York: Basic Books.

Lewis, M. (1997). Altering fate: Why the past does not predict the future. New York: The Guilford Press.

Miller, S. D., Duncan, B. L., \& Hubble, M. A. (1997). Escape from Babel. New York: W.W. Norton.

Mills, R. (1995). Realizing mental health: Toward a new psychology of resiliency. New York: Sulzburger \& Graham.

Peele, S. (1989). The diseasing of America. Lexington, MA: Lexington Press.

Peele, S., \& Brodsky, A. (1991). The truth about addiction and recovery. New York: Simon \& Schuster.

Rapp, C.A. (1998). The strengths model: Case management with people suffering from severe and persistent mental illness. New York: Oxford University Press.

Rieff, D. (1991). Victims all. Harper's Magazine, October, 49-56.

Rogers, C. (1951). Client-centered therapy: Its current practice, theory, and implications. Chicago: Houghton-Mifflin.

Saleebey, D. (1996). The strengths perspective in social work practice: Extensions and cautions. Social Work, 41, 295-305.

Saleebey, D. (Ed.). (1997). The strengths perspective in social work practice. New York: Longman.

Saleebey, D. (in press). The Diagnostic Strengths Manual? Social Work.

Snyder, C. R. (2000). Hypothesis: There is hope. In C. R. Snyder (Ed.), Handbook of hope: Theory, measures, and application (pp. 3-24). San Diego, CA: Academic Press.

Strupp, H. H. (1995). The psychotherapist's skills revisited. Clinical Psychology, 2, 70-74.

Swadener, B. B. (1995). Children and families "at promise:" Deconstructing the discourse of risk. In B. B. Swadener \& S. Lubeck (Eds.), Children and families "at promise": Deconstructing the discourse of risk (pp. 17-49). Albany: SUNY Press.

Weick, A., \& Saleebey, D. (1995). A postmodern approach to social work practice. Paper presented at Adelphi University, School of Social Work, Garden City, New York.

Wolin, S. J., \& Wolin, S. (1993). The resilient self: How children of troubled families rise above adversity. New York: Villard.

\section{Author's Note:}

Address correspondence to: Dennis Saleebey, Ph.D., Professor, University of Kansas School of Social Welfare, Twente Hall, Lawrence, Kansas 66045 USA. 